\title{
A PRIMAZIA DA NATUREZA ANTE O ESPÍRITO EM LUDWIG FEUERBACH
}

\begin{abstract}
Eduardo Ferreira CHAGAS ${ }^{1}$
O homem, por não reconhecer a majestade da Natureza, deixou-se cair numa infantil exaltação diante do domínio adquirido e sempre crescente sobre os elementos dela. Mesmo quando se pavoneava como um deus em sua própria imaginação, abatia-se sobre ele uma pueril imbecilidade. Como era de prever-se desde a origem de sua doença, foi crescendo infectado de sistemas e de abstrações.
\end{abstract}

(Edgar Allan Poe, Colóquio entre Monos e Una)

- RESUMO: O presente artigo pretende destacar a tese de que a natureza para Feuerbach é um existente autônomo e independente e possui primazia ante o espírito. Para ele, a natureza material, que existe, em sua diferencialidade qualitativa, independente do pensar, é diante do espírito o original, o fundamento não deduzível, imediato, não criado, de toda existência real, que existe e consiste por si mesmo. Feuerbach opõe a natureza ao espírito, pois ele a entende não como um puro outro, que só por meio do espírito foi posto como natureza, mas como o primeiro, a realidade objetiva, material, que existe fora do entendimento e é dada ao homem, por meio de seus sentidos, como fundamento e essência de sua vida. Trata-se, pois, primeiro daquela essência (luz, ar, água, fogo, plantas, animais etc.) sem a qual o homem não pode nem ser pensado nem existir. A natureza é, para Feuerbach, a pluralidade de todos os objetos e essências que realmente são. Sob esta condição, é possível conceber a natureza como a garantia da exterioridade mesma, como que um existente fora de nós, que nada sabe de si e é em si e por si mesmo; por conseguinte, ela não deve ser vista como aquilo que ela não é, isto é, nem como divina, nem como humana. A natureza sempre existiu, quer

1 Professor adjunto da graduação e da pós-graduação do Departamento de Filosofia da Universidade Federal do Ceará (UFC) e colaborador do Programa de Pós-Graduação da Faculdade de Educação (Faced) da UFC. Artigo recebido em 03/2009 e aprovado em 11/2009. 
dizer, ela existe por si e tem seu sentido apenas em si mesma; ela é ela mesma, ou seja, nenhuma essência mística, pois, por trás dela, não se esconde nenhum absoluto, nada humano, nada divino, transcendental ou ideal.

- PALAVRAS-CHAVE: conceito de natureza em Feuerbach, crítica ao teísmo e ao idealismo, Feuerbach, Marx.

No presente trabalho, enfatizo a filosofia da natureza de Ludwig Feuerbach como cerne de sua oposição ao teísmo (seja ao cristianismo, seja ao paganismo), à filosofia especulativa e ao idealismo alemão (Fichte, Schelling e Hegel). Feuerbach recusa tanto o teísmo quanto o idealismo e, perante ambas as posições, faz valer a noção de que a natureza, apesar de sua mutabilidade (na qualidade de um desenvolvimento contínuo de intervenções, de uma justaposição de momentos evolucionais e "catastrofais"), deve ser entendida e esclarecida como um existente autônomo, independente, como algo eterno, não deduzível, objetivo e necessário. A natureza é, pois, o ser primeiro, o que origina, o que produz tudo de si, e não pode ser pensada como produzida, pois ela existe por si e tem seu sentido tão somente em si mesma. Ademais, ela é para Feuerbach não só o que limita, mas também a potência (das Vermögen) que assegura ao homem a possibilidade, a condição, de satisfazer suas necessidades múltiplas; ela é, pois, aquela essência (luz, ar, água, fogo, plantas, animais etc.) sem a qual o homem não pode nem ser pensado nem existir. Natureza, assim diz ele, "é tudo o que se mostra ao homem, abstraído das sugestões supranaturais da crença teística, imediatamente, sensorialmente, como base e objeto de sua vida" (Feuerbach, 1967, p. 104). Sob esta consideração, deve-se conceber a natureza como a garantia da exterioridade mesma, como que um existente fora de nós que nada sabe de si e é em si, de si e por si mesmo.

Embora a concepção de natureza de Feuerbach não seja atomísticomecanicista, já que, para ele, a natureza não é nenhuma máquina, nenhuma pura res extensa, sem vida, nenhuma grandeza lógico-matemática, isto é, nenhum universo que se movimenta necessariamente segundo leis mecânicas, de acordo com ele, "sensibilidade", "vivacidade", "vitalidade", "fisicalidade", "exterioridade" são conceitos similares para a existência material da natureza, pois a natureza que existe real e objetivamente expressa sua existência material mediante efeitos físicos, fenômenos naturais que existem não apenas idealmente no entendimento, mas também constituem para o homem efeitos sensíveis, observados sensivelmente. Assim compreendido, mediante um entendimento da natureza que se baseia nas características imanentes a ela - totalidade, unidade orgânica, harmonia de causas e efeitos, movimento, "imediaticidade", autonomia, lei (legalidade ou regularidade), necessidade, como pressupostos necessários para todos os obje- 
tos, fenômenos e criaturas, plantas e animais, até mesmo para a natureza humana -, Feuerbach critica tanto o teísmo quanto o idealismo, os quais ignoram a autonomia (Selbständigkeit) e a independência (Unabhängigkeit) da natureza, uma vez que eles a compreendem meramente como obra de um criador ou como um simples ser outro do espírito na exterioridade. Em ambas as posições, a natureza foi tratada, portanto, não como um existente autônomo, independente, mas deduzida apenas como uma realidade dependente e inconsistente em si mesma (Chagas, 2003, p. 70).

As teses fundamentais do conceito de natureza em Feuerbach contra o teísmo e o idealismo podem ser sintetizadas assim:

- a natureza é, em primeira linha, uma verdade dada aos sentidos. Como objeto dos sentidos (als Gegenstand der Sinne), ela não é uma deduktion do espírito, nem criação de Deus; ou seja, ela não é um produto nem da atividade de um eu puro, do desenvolvimento do espírito, nem da vontade de um Deus sobrenatural, fictício, mas, pelo contrário, é uma essência autônoma que existe independentemente da consciência humana.

Natureza [...] é tudo o que tu vês e não provém das mãos e dos pensamentos humanos. Ou, se quisermos penetrar na anatomia da natureza, ela é o cerne ou a essência dos seres e das coisas, cujos fenômenos, exteriorizações ou efeitos, nos quais exatamente sua essência e existência se revelam e dos quais constam, não têm seu fundamento em pensamentos, intenções ou decisões do querer, mas em forças ou causas astronômicas, cósmicas, [...] químicas, físicas, fisiológicas ou orgânicas. (Feuerbach, 1967, p. 105)

- a natureza é incriada (unerschaffen), eterna (unvergänglich), não deduzível (nicht ableitbar); ela é em si mesma, existe apenas por si mesma e não por meio de outra essência;

- a natureza é necessária (notwendig). Porque ela é, é ela necessária, e exatamente assim como é, isto é, correspondendo às suas próprias leis. Se, a saber, tudo o que é, é necessariamente por meio da natureza, assim não tem sentido aceitar um espírito ou um Deus criador que planeja para o esclarecimento da natureza e, por fim,

- a natureza corresponde apenas a si mesma. A palavra "natureza" designa, assim esclarece Feuerbach,

o cerne de todas as forças, coisas e seres sensíveis que o homem distingue de si como não-humanas. Entendo em geral sob natureza, certamente como Spinoza, não um ser como o Deus supranaturalístico, que existe e age com vontade e razão, mas que atua somente conforme a necessidade de sua natureza; mas ela não é para mim, como é para Spinoza, um Deus, ou seja, um ser ao mesmo tempo sobrenatural, transcendente, deduzido, misterioso, simples, e sim um ser múltiplo, [...] real, perceptível com todos os sentidos. (Feuerbach, 1967, p. 104) 
A natureza é, pois, apenas explicável, quando se reconhece que ela não é nenhum ser abstrato, despojado de existência, mas a unidade da diversidade das coisas que são reais, concretas; ou melhor, ela é a multiplicidade dos entes singulares, e fora dela nada tem existência real, a não ser pensamentos e representações.

Ante o teísmo e o idealismo, que deduzem a natureza de Deus ou do espírito, Feuerbach argumenta o seguinte:

- a natureza precede o espírito e, por isso, é sua base orgânica;

- o espírito é, pelo contrário, um produto da natureza, pois o pensamento é também uma funktion de um órgão natural, do cérebro humano, ou seja, uma atividade que não está fora do corpo e dos sentidos; e

- Deus, como criador (als Schöpfer) da natureza, do mundo, é, em verdade, apenas o espírito do homem pensado universalmente. A aceitação de um Deus, de uma criação espiritual da natureza, por assim dizer, de uma transferência das representações do pensamento sobre a natureza, está em completa oposição à existência da natureza.

Ex nihilo nihil fi, do nada nada vem, isto é uma lei geral da natureza e da razão, válida universalmente. Um mundo, criado em oposição a esta lei fundamental, é uma contradição consigo mesmo, uma contradição com todas as leis da natureza; é, em síntese, o mundo invertido da teologia, em que o pensamento é anterior à matéria e ao objeto do pensamento, ou seja, a criança anterior à mãe, a grama ao sol. (Feuerbach, 1969, p. 259)

\section{Feuerbach acentua:}

Se não estou louco, como posso deixar nascer seres irracionais de um ser racional? Como pode um espírito produzir seres sem espírito? [...] Tem-se dito frequentemente: "o mundo é inexplicável sem um Deus", mas o exato oposto é verdadeiro: "se um Deus existe, é a existência de um mundo inexplicável, porque ela é inteiramente supérflua". (Feuerbach, 1967, p. 161-2)

À objeção teístico-idealista "como pode o homem surgir da natureza, ou seja, o espírito da matéria", opõe Feuerbach o seguinte:

Responda-me, sobretudo, primeiro a pergunta: Como pode nascer do espírito a matéria? Tu não achas para esta pergunta nenhuma resposta, pelo menos racional, assim tu reconhecerás que apenas a resposta oposta conduz a ti para o objetivo. (Feuerbach, 1971, p. 179)

Não a dedução do espírito da natureza, mas, pelo contrário, a deduktion da natureza do espírito é, pois, um problema insolúvel. Para Feuerbach, é, 
por conseguinte, racional começar com a natureza e só daqui passar para o homem, para o espírito.

Os argumentos, que se poderiam expor para a defesa da tese feuerbachiana no que tange ao primado da natureza e do nascimento do homem dela, ou seja, do esclarecimento da natureza por ela mesma, podem ser apresentados, resumidamente, assim:

- a natureza não pode ser deduzida do espírito, já que ela possui uma qualidade completamente diferente dele; mas o espírito pode ser deduzido dela e esclarecido por ela, porque o homem, como criação da natureza, é a identidade de todas as oposições, isto é, a unidade do espiritual com o natural. O homem, no qual a natureza veio à consciência, sabe de si, conhece a si mesmo como unidade real, viva, do espírito e do corpo, de todas as qualidades ativas e passivas, espirituais e sensíveis. Aqui se encontra, para Feuerbach, o cerne verdadeiro da unidade do pensar e do ser, pois o pensamento humano, como sujeito autônomo,

que não tem mais fora de si nenhuma coisa e, por conseguinte, mais em si nenhum limite, não é mais sujeito "finito" - não é mais o eu, ao qual se contrapõe um objeto -, é o ser absoluto, cuja expressão teológica ou popular é a palavra "Deus". É, na verdade, o mesmo sujeito, o mesmo eu, como no idealismo subjetivo - mas sem limites, o eu que já não parece também ser eu, essência subjetiva, e, por conseguinte, também já não se chama mais eu. (Feuerbach, 1970, p. 299)

O espírito (o eu) não é, pois, apenas sujeito para si, mas também simultaneamente predicado de uma essência real; ou seja, ele não é, de modo nenhum, por si mesmo enquanto tal, mas por si como essência corporal, sensível; pela corporeidade, ele está aberto à natureza, ao mundo, pois estar no corpo quer dizer nada mais do que estar no mundo;

- A natureza não pode ser deduzida do espírito, porque o inferior (das Niedere, o anterior = a natureza) não pode ser esclarecido e deduzido do superior (das Hörere, do posterior = o espírito), mas antes, pelo contrário, o superior do inferior, como todo desenvolvimento prova. Deduzir a natureza do espírito é, por conseguinte, ilógico, sem sentido, pois por que se deve fazer passar o "superior" por algo "inferior", o komplex pelo simplex, o "perfeito" (desenvolvido) pelo "imperfeito" (não-desenvolvido)? Feuerbach defende o argumento de que a natureza produziu de si mesma o homem; ou seja, ela é a essência, da qual o homem nasceu e pela qual mantém sua existência. A natureza é

o que compreende o homem; ela é aquilo cuja aniquilação significa também a própria aniquilação da existência humana; somente através dela consiste o homem, somente 
dela depende ele em toda a sua atividade, em todos os seus passos. Arrancar o homem da natureza significa o mesmo que separar os olhos da luz, o pulmão do ar, o estômago dos alimentos e querer fazer deles seres existentes por si mesmos. (Feuerbach, 1967, p. 91)

O homem é um produto da natureza, uma obra dela; ele deve, por isso, tratá-la e estimá-la como "sua mãe", como a fonte de seu ser. Já que ele deve seu nascimento e sua manutenção apenas às forças e aos efeitos naturais, depende ele, por conseguinte, da natureza; quer dizer, ele não é nenhum ser sem necessidade, mas um organismo que pressupõe as determinações da natureza, água, ar, alimento etc.;

- por fim, considerar o espírito como a premissa da natureza é sem sentido, pois não se pode indicar de onde este toma a determinação para a matéria. Não é, portanto, o espírito a origem e a razão de ser da matéria; pelo contrário, a natureza (a matéria) deve ser vista como o fundamento do espírito, isto é, como um fundamento que não tem nenhum fundamento fora de si mesmo. O espírito, a consciência, pode desenvolver-se, assim, apenas da natureza orgânica; na verdade, ele é, no homem, o superior, pois, por meio dele, o homem diferencia-se do animal (Feuerbach, 1970, p. 335-6). ${ }^{2}$ Isto não significa, de modo nenhum, que ele seja o primeiro de acordo com o desenvolvimento natural. O espírito, isto é, o superior, o completo, é, ao contrário, resultado, sempre o último, o posterior. No espírito humano, a natureza atinge o auge de seu desenvolvimento; aí ela se torna um ser pessoal, autoconsciente, inteligível; ou seja, no ho-

2 Nos Princípios da filosofia do futuro (Grundsätze der Philosophie der Zukunft), Feuerbach chama a atenção para o fato de que o homem de nenhum modo se distingue do animal só pelo pensamento. "Seu ser todo é, pelo contrário, o que o distingue do animal." Ele indica ainda: "O homem não é um ser particular como o animal, mas um ser universal, por conseguinte, não é um ser limitado e sem liberdade, mas um ser ilimitado e livre, pois universalidade, não limitação e liberdade são inseparáveis. E esta liberdade também não reside numa faculdade particular, no querer; na verdade, da mesma maneira que esta universalidade não se encontra numa disposiç̧ão especial da faculdade de pensar, na razão, esta liberdade, esta universalidade estende-se ao seu ser total. Sem dúvida, os sentidos animais são mais apurados do que os humanos, mas apenas em relação a coisas determinadas, necessariamente conexas com as necessidades do animal, e são mais agudos justamente por causa desta determination, desta limitação exclusiva a algo de determinado. O homem não tem o faro de um cão de caça, de um corvo; mas apenas porque o seu olfato pode abranger todas as espécies de odores, por isso é um sentido livre e indiferente a respeito de odores particulares. Onde, porém, um sentido se ergue sobre os limites da particularidade e de sua vinculação à necessidade, eleva-se aí a uma significação e dignidade autônomas, teóricas: sentido universal é o entendimento, sensibilidade universal é espiritualidade. Mesmo os sentidos inferiores, o olfato e o paladar, se elevam no homem a atos espirituais e científicos" (Feuerbach, 1970, p. 335-6). 
mem, a natureza torna-se espírito, toma consciência de si mesma. O homem é, pois, um ser qualitativamente diferente de todas as outras formas de existência na natureza (Jessin, 1956, p. 3-41; Höppner, 1960, p. 302-55). ${ }^{3}$

Os méritos da filosofia de Feuerbach, particularmente de sua concepção de natureza, podem ser caracterizados da seguinte maneira:

- Feuerbach almeja provar que a natureza, entendida como algo autônomo (Selbständiges), original, diante do espírito, é a base deste e que, embora o homem esteja, pelo seu corpo, indissoluvelmente ligado a ela, é ela, apesar disto, outra essência, um ser diferente e independente dele, e

- que Deus não é nenhum ser que existe por si, mas meramente uma representação fantástica da essência humana, um projeto puramente idealizado do espírito. Disso conclui Feuerbach que a relação Deus-homem é tão somente uma conexão do homem consigo mesmo, e a separação de Deus do homem é apenas uma separação do homem de si mesmo. Em vez desta relação humano-religiosa voltada para Deus, Feuerbach quer pôr a relação do homem para o homem, para o seu próximo e para a natureza sem Deus (Chagas, 2004, p. 86-105). Para alcançar tal propósito, o homem deve livrar-se de toda fé em forças sobrenaturais e voltar-se apenas para si e para a natureza. Feuerbach aspira a uma relação humana para com a natureza, mediada pela sensibilidade (Sinnlichkeit), pela contemplação sensível da natureza, tal como esta aparece imediatamente ao homem. Ele quer restabelecer uma relação natural para o homem mediante a relação imediata, sensível do amor do eu para o tu, do singular (do indivíduo) para o gênero (para a comunidade), cuja base vale para ele como a relação natural do homem para a mulher.

Em A Sagrada Família (Die heilige Familie) (1844), Marx reconhece expressamente, apesar de toda a sua crítica a Feuerbach, o significado positivo, a relevância de sua filosofia para a história da dialética e do espírito humano:

Mas, afinal, quem revelou o mistério dos "sistemas"? Feuerbach. Quem aniquilou a dialética dos conceitos, a guerra dos deuses, que apenas os filósofos conhecem? Feuerbach. Quem colocou, na verdade, "o significado do homem" - como se o homem tivesse ainda uma outra significação a não ser a de ser homem! -, pelo me-

3 A respeito dessas teses ora levantadas, que dão primazia à natureza ante o espírito, conferir os trabalhos de Höppner, 1960, p. 302-55; e Jessin, 1956, p. 3-41. 
nos "o homem" no lugar dos farrapos velhos, da "consciência de si infinita"? Feuerbach, e somente Feuerbach. Ele fez ainda mais. Depois de muito tempo, ele aniquilou estas mesmas categorias, que a "crítica" lança agora a si: A riqueza real das relações humanas, o conteúdo enorme da história, a luta da história, a luta da massa contra o espírito etc. (Marx, 1958, p. 98)

\section{E, nos Manuscritos econômico-filosóficos (Ökonomisch-philosophi- schen Manuskripten) (1844), ele esclarece:}

Feuerbach é o único que tem uma relação séria e crítica para com a dialética hegeliana e realizou, neste campo, verdadeiras descobertas; acima de tudo, foi quem superou verdadeiramente a antiga filosofia. A grandeza da obra de Feuerbach e a silenciosa simplicidade com que a apresenta ao mundo estão em um surpreendente contraste com o comportamento dos outros. (Marx, 1968, p. 569)

Não se pode deixar, segundo Marx, de referendar os grandes empreendimentos da filosofia de Feuerbach, na medida em que ela é, em síntese:

- a prova de que a filosofia (especulativa) nada mais é do que a religião convertida em pensamento e realizada pelo pensamento; deve condenar-se como uma outra forma e uma outra maneira de existência do estranhamento do ser humano;

- a fundamentação do materialismo autêntico e da ciência real, na medida em que Feuerbach faz da relação social "do homem ao homem" o princípio básico da teoria; e

- oposta à negação da negação, que pretende ser o positivo absoluto, o princípio subsistente em si e fundado positivamente em si mesmo. (Marx, 1968, p. 569-70)

Apesar dessas realizações de Feuerbach, principalmente no que diz respeito a seus protestos contra o teísmo e o idealismo, não se deve, no entanto, descuidar da crítica a sua filosofia no todo por causa de suas "contradições", "limitações" e "inconsequências".

Em referência à filosofia de Feuerbach, Marx reconhece que, para ela, o homem é

um ser corpóreo, dotado de forças naturais, vivo, real, sensível, objetivo, ou seja, que ele tem objetos reais, sensíveis como objetos do seu ser, da exteriorização de sua vida, ou que pode exteriorizar a sua própria existência só em objetos reais, sensíveis. Ser objetivo, natural, sensível e simultaneamente ter fora de si o objeto, a natureza, o sentido para um terceiro ser é a mesma coisa. A fome é uma necessidade natural; ela precisa, portanto, de uma natureza fora de si, de um objeto fora de si, para se satisfazer, para se acalmar. A fome constitui a necessidade objetiva de um corpo por um objeto exterior, indispensável à sua integração e à expressão da própria natureza. [...] [E] o homem, como ser objetivamente sensível, é, por conseguinte, um ser que sente e, porque sente o seu sofrimento, um ser afetivo. A emoção intensa, a pas- 
sion [a paixão] é a força essencial [a faculdade] do homem que se esforça energicamente para alcançar o seu objeto. (Marx, 1968, p. 578-9)

A essência humana não é, no entanto, para Marx, como o é para Feuerbach, nenhuma essência abstrata, mas, pelo contrário, uma essência concreta, social e histórica, isto é, uma essência que se realiza na história pela atividade, pela práxis social. Marx pensa o homem como um ser que se manifesta no trabalho; ele é o que ele é pelo seu trabalho, pela sua produtividade. Correspondendo a isto, Marx diz na Ideologia alemã (Deutsche Ideologie) (1845-6):

Podem-se distinguir os homens dos animais pela consciência, pela religião ou por tudo o que se queira. Mas eles próprios começam a se diferenciar dos animais logo que começam a produzir seus meios de vida, passo este que é condicionado por sua organisation [organização] corporal. Na medida em que os homens produzem seus meios de vida, produzem eles, indiretamente, sua própria vida material. (Marx, 1969, p. 21)

Embora Feuerbach acentue, muitas vezes, que o homem é um ser sensível, natural, o ser que se tornou social, no fundo, permanece o homem para ele um abstraktum inerente ao indivíduo isolado, isto é, um ser fixo, segregado, abstraído do decurso histórico, e sua "relação social" foi concebida por ele apenas como uma relação genérica, como uma universalidade puramente natural que se liga a muitos indivíduos. Por conseguinte, Feuerbach não vê, e a ele isto permanece, infelizmente, sem consideração, que o homem, além de ser uma essência sensível, nascida da natureza, é também um produto dele mesmo (ein Produkt des Menschen), da cultura, da história. Do mesmo modo, ele desconhece igualmente o nascimento e o desenvolvimento histórico da existência do homem e de sua consciência com base na apropriação material da natureza, na produktion submetida a determinada relação social, e o abstrai completamente de suas relações socioeconômicas e políticas, porque ele não o entende como "ensemble", como membro da sociedade (Glied der Gesellschaft).

O objeto da filosofia da natureza de Ludwig Feuerbach é não só a natureza incriada, autônoma, a prioridade, o primado da natureza externa (das Primat der äusseren Natur), exterior (ainda não dominada pelos homens), como também a natureza em relação ao homem. Naturalismo e humanismo são quase um, pois, conforme Feuerbach, o homem é um produto da natureza, um ser mesmo da natureza. Uma filosofia da natureza sem o homem e, do mesmo modo, uma filosofia sem natureza parecem para ele sem sentido, um absurdo. O problema encontra-se, porém, nisso, a saber, que ele não chegou a uma concepção materialista consequente nem da na- 
tureza nem daquilo que diz respeito às relações natureza-homem e homemhomem, já que ele:

- absolutiza a natureza e a concebe apenas "naturalmente", sensivelmente (como objeto da intuição sensível), e não, ao mesmo tempo, histórico-socialmente (como produção da práxis humana), e

- conceitua natureza e homem não em sua relação real, dialética. Feuerbach exclui de facto a história da relação do homem com a natureza, e esta daquela. Conquanto conceba a natureza como um objeto real e esclareça que o homem tenha surgido dela e ela lhe seja dada pelos sentidos, ele não percebe, todavia, que a natureza, que envolve o homem, não permanece eternamente idêntica, sempre igual a si mesma, mas é transformada, modificada praticamente pelo homem. Enquanto a natureza lhe aparece, portanto, meramente como um ser estático, imediato, Marx a depreende, pelo contrário, como um

produto da indústria e das condições da sociedade; e, na verdade, no sentido de que é um produto histórico, o resultado da atividade de toda uma série de generationen [gerações], cada uma das quais ultrapassava a precedente, desenvolvendo sua indústria e seu comércio, modificando sua ordem social em função da modificação das necessidades. Mesmo os objetos da mais simples "certeza sensível" só são dados a Feuerbach [ao homem] apenas através do desenvolvimento social, da indústria e do intercâmbio comercial. (Marx, 1969, p. 43)

Em Feuerbach a relação entre o homem e a natureza permanece, ao contrário, fixa (starr), não dinâmica, pois, como consequência de sua opposition ante o teísmo e o idealismo, ou seja, ante toda forma de antropomorfização da natureza, ele designa a natureza como "a essência sem essência humana", sem "qualidades humanas", como a natureza sem o homem. Diz ele:

"Natureza" é para mim, tal como é o espírito, nada mais do que uma palavra universal para a designação das essências, das coisas, dos objetos, os quais o homem diferencia de si e de seus produtos e resume no nome comum "natureza", mas não é nenhuma essência geral, personificada, mistificada, separada e abstraída das coisas reais. (Feuerbach, 1971, p. 4)

Ademais, Feuerbach tem "diante dos olhos", no conceito de "produto", não algo social-histórico, mas apenas o que é resultado abstrato da atividade humana, depreendido como "illusion" de uma essência criada pelo homem, que está acima da natureza. Em conformidade com isto, ele trata a realidade objetiva (gegenständliche Wirklichkeit) como algo preso ao objeto; quer dizer, ele vê apenas seu lado objetivo, mas não o subjetivo, porque ele concebe a Aktivität do sujeito não como práxis material, histórico-social, 
como atividade produtiva, mas tão somente como contemplação, como intuição sensível (sinnliche Anschauung). Isto expressa o conteúdo, o sentido da primeira Tese sobre Feuerbach (Thesen über Feuerbach), mediante a qual Marx caracteriza a carência principal de todo materialismo anterior, inclusive o de Feuerbach. Precisamente o lado ativo do sujeito, que produz o objeto, não foi desenvolvido por Feuerbach, mas pelo idealismo de Kant, Fichte e Hegel, embora apenas subjetivamente, como atividade do entendimento, do eu que age, do espírito que se desdobra para o mundo. A filosofia de Feuerbach permanece, pois, atrás dessa práxis já desenvolvida pelo idealismo; ela não consegue transformar a atividade prática, concebida idealmente, numa atividade prático-crítica, real, material (Löwith, 1976, p. 149-50).

Para Marx, o mundo material é, ao contrário, um todo unitário, no qual todas as formas de dualismo estão rejeitadas; esse mundo material encontra-se também de novo na consciência, e isto se torna claro sobretudo no processo de trabalho. Quanto a isto, Hegel já tinha, na Fenomenologia do espírito (Phänomenologie des Geistes), mediante a dialética do senhor e do servo, caracterizado o trabalho como processo que supera a resistência da natureza, no qual o homem toma consciência de si mesmo, de sua espiritualidade, pois, na medida em que o homem trabalha, ele manifesta sua própria essência e impõe à natureza uma forma humana; assim, ele avista, no resultado de seu trabalho, não um produto que está diante dele, mas, pelo contrário, sua realidade tornada objetiva. Esta essência positiva do trabalho, entendida como processo dialético de autoprodução do homem e transformação da natureza, foi também postulada por Marx. Trabalho é, para ele,

antes de tudo, um processo entre homem e natureza [processo de que participam o homem e a natureza], processo em que o homem, através de sua própria ação, medeia, regula e controla seu intercâmbio material com a natureza. Ele se defronta com a natureza como uma de suas forças. Põem-se em movimento as forças naturais que pertencem ao seu corpo, braços e pernas, cabeça e mãos, a fim de apropriar-se dos recursos da natureza, imprimindo-lhes forma útil para a sua própria vida. $\mathrm{Na}$ medida em que ele atua assim, através de seu movimento sobre a natureza externa a ele e a transforma, simultaneamente transforma ele a sua própria natureza. (Marx, 1977, p. 192)

Isso porque a reciprocidade entre homem e natureza encontra-se na atividade produtiva, no interior de uma organization determinada socialmente, mediante a qual o homem muda a natureza e cria algo, como também produz e modifica sua natureza social. E é, precisamente, por intermédio deste metabolismo material, deste intercâmbio do homem com a natureza que ocorre o acesso a declarações sobre a origem e o desenvolvi- 
mento do homem. Já que Feuerbach concebe abstratamente a relação do homem para com a natureza, isto é, não conhece nenhuma relação recíproca, dialético-dinâmica entre eles, falta a ele também o entendimento de que "a história da natureza" (Naturgeschichte) e a "história da humanidade" (Menschheitsgeschichte) formam unidade interna, pois o homem, como uma parte real da natureza (o tornar da natureza para o homem), tem uma "natureza histórica" e uma "história natural" (Marx, 1969, p. 43).

A acepção de natureza em Feuerbach é naturalista, não mediada pela história, pois falta a ela o sentido para a história, para as condições concretas, sociais, do homem. Na medida em que Feuerbach considera, como visto, a relação entre homem e natureza, não do ponto de vista da atividade prático-crítica, mas apenas da perspectiva da intuição sensível, ele não percebe que por trás desta relação está a história, a sociedade, que possui ela mesma uma base social, uma fundamentação material-econômica. Para Marx, o homem tem, ao contrário, uma vida essencialmente prática, produtiva, que pertence a uma forma determinada da sociedade; ele é, como mencionado,

não apenas um ser natural, mas um ser natural humano; quer dizer, um ser existente para si mesmo, por isso, um ser genérico, e, como tal, tem de confirmar-se e expressar-se tanto no seu ser como no seu saber. Então, nem os objetos humanos são objetos naturais, como eles se apresentam imediatamente, nem o sentido humano, tal como ele é imediata e objetivamente, é sensibilidade humana, objetividade humana. Nem a natureza objetiva, nem a natureza subjetiva se apresenta imediatamente ao ser humano de forma adequada. E, assim como tudo o que é natural deve ter a sua origem, também o homem tem o seu ato de nascimento, a história, que é, no entanto, para ele, uma [história] consciente, e, por isso, enquanto ato de gênese com consciência, é um ato de gênese que se suprassume [se transcende a si próprio]. A história é a verdadeira história da natureza do homem. (Marx, 1968, p. 579)

Assim, para Marx, a história é a natureza real do homem, pois o homem, como ser social, é determinado, em princípio, não pela natureza. A natureza tem sua existência para o homem precisamente na história, assim como o homem encontra para o homem, na natureza e na apropriação histórico-social dela, sua existência e essência. A concepção de natureza em Feuerbach encontra-se, ao contrário, não no âmbito da relação concreta do homem para a natureza, da práxis humana, porquanto ele ignora o conceito de trabalho como relação do homem para a natureza, do homem para o homem. Na sociabilidade capitalista, a natureza possui para o homem uma existência estranha, "não humana", porque ele mesmo se comporta aqui como uma existência estranha, "não natural", "inumana", e o fundamento desta sua "inumanidade" é a divisão forçada do trabalho ligada à propriedade privada. A superação da "dimension" da "inumanidade" do homem, do 
estranhamento da relação humana para o próximo e para a natureza (para seu meio ambiente) não pode ser realizada, como Feuerbach acreditara, simplesmente pela negation das illusionen religiosas, fantásticas. A raiz real, social e política da religião é completamente estranha a Feuerbach, por isso é para ele o estranhamento (Entfremdung) apenas uma forma psicológica, antropológica, da consciência humana invertida, que duplica o mundo numa realidade real e representada, e apresenta a natureza e o homem de uma maneira não natural, estranha à sua natureza. Feuerbach fixa o sentimento religioso (religiöse Gemüt) como algo para si existente e não vê, por conseguinte, que ele é também um produto social. A isto se relaciona ainda o fato de que ele não compreende que a emancipação do homem do estranhamento religioso pressupõe a superação de sua causa e fonte, isto é, de suas condições materiais, sociais e econômicas, fundadas na propriedade privada dos meios de produção.

Enfim, deve ser, no todo, constatado o fato de que Ludwig Feuerbach não consegue, em verdade, nem interpretar materialmente a vida social, a história, nem esclarecer as relações econômicas, nas quais se devem procurar os fundamentos para o estranhamento humano. Não deve ser aqui esquecido, porém, o fato de que ele não tinha posto para si as mesmas prioridades que tinham Hegel e Marx. É preciso ter bem clara ainda a noção de que o pensamento de Feuerbach não se movimenta nem no círculo do processo da autoconsciência, como em Hegel, nem no mundo histórico do trabalho, como em Marx; ele tem, pelo contrário, por objeto o imediato (das Unmittelbare), ou seja, a natureza e a sensibilidade (die Sinnlichkeit). Diante de Hegel e Marx, quer Feuerbach conceder à natureza prioridade, requer o indubitável, o não deduzível, o elementar, o simples, do qual se eleva para o mediato e o deduzido. Com base neste fundamento, é para ele possível garantir a autonomia (Selbständigkeit) e a independência (Unabhängigkeit) da natureza apenas pela crítica ao começo sem pressuposto, ou seja, à "imediatidade" imediata (na forma de Deus ou do espírito), como afirmado pelo teísmo e pelo idealismo, pois tanto um quanto o outro se baseiam, em verdade, não na "imediaticidade" dada sensivelmente (a "imediaticidade" da natureza), mas sempre num ato já refletido e produzido pelo homem.

CHAGAS, Eduardo Ferreira. The primacy of nature against the spirit in Ludwig Feuerbach. Trans/Form/Ação, São Paulo, v.32(2), 2009, p.119-133.

- ABSTRACT: This article tries to delineate the proposition that to Feuerbach nature is an autonomous and independent being that comes first in comparison to the spirit. To him, material nature, that exists in its qualitative differentness, independent from thinking, is the original source, the immediate, not deductible, 
uncreated fundament of all real existence, that exists and consists in itself, when put vis-à-vis the spirit. Feuerbach sets nature against the spirit, for it is his understanding that nature is not a pure other that only through the spirit was set as nature, but as the first source, the objective material reality that exists outside reason and is given to man by means of his senses as fundament and essence of his life. Therefore, one is dealing first with that essence (light, air, water, fire, plants, animals etc.) without which man does not exist or could be thought of as existing. To Feuerbach nature is all objects and essences put together. Under this condition it is possible to conceive nature as guarantor of externality itself as if it could exist independently from us, an entity that is unaware of itself and which exists in itself and by itself; for this reason it shall not be seen as something which it is not, i.e., neither divine nor human. Nature always existed, i.e., it exists in itself and has only meaning in itself; it is itself, i.e., it has no mystical essence, it does not hide behind it any absolute being whether human, divine, transcendental or ideal.

- KEYWORDS: concept of nature according to Feuerbach, the critique of theism and idealism, Feuerbach, Marx.

\section{Referências bibliográficas}

ARVON, Henri. Ludwig Feuerbach ou la transformation du sacré. Paris: Presses Universitaires de France, 1957.

CHAGAS, Eduardo F. Projeto de uma nova filosofia como afirmação do homem em Ludwig Feuerbach. Teoria \& Praxis - Revista de Ciências Humanas e Política, n 4, 1992, Goiânia (GO), p. 31-6.

A autonomia da natureza em Ludwig Feuerbach. In: VASCONCELOS, J. G. (Org.). Filosofia, educação e realidade. Fortaleza (CE): Editora UFC, 2003, p. 69-79.

. Religião: O homem como imagem de Deus ou Deus como imagem do homem? In: OLINDA, E. M. B. Formação humana: liberdade e historicidade. Fortaleza (CE): Editora UFC, 2004, p. 86-105.

Kritik des Anfangs der Philosophie Hegels in der Logik und Phänomenologie des Geistes. In: Festschrift zu Hans-Georg Flickinger. Göttingen: Civilier, 2004, p. 63-76.

Feuerbach e Espinosa: Deus e natureza, dualismo ou unidade? In: Trans/ Form/Ação, 2006, v. 29, n² 2, p. 79-93, ISSN 0101-3173.

FEUERBACH, L. Vorlesungen über das Wesen der Religion, GW 6. Org. por W. Schuffenhauer. Berlim: Akademie, 1967.

Theogonie nach dem Quellen des klassischen, hebräischen und christlichen Altertums, GW 7. Org. por W. Schuffenhauer. Berlim: Akademie, 1969.

Grundsätze der Philosophie der Zukunft, GW 9. Org. por W. Schuffenhauer. Berlim: Akademie, 1970. 
FEUERBACH, L. Das Wesen der Religion, GW 10. Org. por W. Schuffenhauer. Berlim: Akademie, 1971.

. Fragmente zur Charakteristik meines philosophisches curriculum vitae, GW 10. Org. por W. Schuffenhauer. Berlim: Akademie, 1971.

HEGEL, Georg Wilhelm Friedrich. Phänomenologie des Geistes. Org. por W. Bonsiepen e R. Heede. Hamburgo: Felix Meiner, 1999.

HÖPPNER, Joachim. Ludwig Feuerbach und seine materialistische Weltanschauung in ihrer historischen Bedeutung für die wissenschaftliche Philosophie. Phil. Diss., Leipzig, 1960.

JESSIN, I. M. Die materialistische Philosophie Ludwig Feuerbachs. Berlim: Dietz, 1956.

LÖWITH, Karl. Vermittlung und Unmittelbarkeit bei Hegel, Marx und Feuerbach. In: Ludwig Feuerbach. Org. por Erich Thies. Darmstadt, 1976.

MARX, K. Ökonomisch-philosophische Manuskripte (1844), MEW, Ergänzungsband. Berlim, 1968. Das Kapital, MEW, v. 23. Berlim, 1977.

MARX, K.; ENGELS, F. Die heilige Familie, MEW, v. 2. Berlim, 1958. Deutsche Ideologie, MEW, v. 3. Berlim, 1969.

SCHMIDT, Alfred. Emanzipatorische Sinnlichkeit. Ludwig Feuerbachs anthropologischer Materialismus. Munique: Carl Hanser, 1973.

TOMASONI, Francesco. Ludwig Feuerbach e la natura non umana: Riconstruzione genetica dell' "Essenza della religione" con pubblicazione degli inediti. Florença: La Nuova Italia, 1986. 